Vol 2 No 2 Desember 2021

Jurnal AlphaEuclidEdu

Received: 05/05/2021; Resived: 11/10/2021; Accepted: 28/12/2021

\title{
KAJIAN ETNOMATEMATIKA DALAM TRADISI PERNIKAHAN MASYARAKAT DAYAK KANAYATN DI KECAMATAN TOHO KABUPATEN MEMPAWAH
}

\author{
Eka, Sugiatno, Munaldus \\ Program Studi Pendidikan Matematika FKIP Untan Pontianak \\ Email: $\underline{\text { ekamrdn98@gmail.com }}$
}

\begin{abstract}
The purpose of the research is to know Dayak Kanayatn Custom as a mathematical aspect in Marriage related to ethnomathematics studies to be used in mathematics learning in schools and mathematical aspects contained in the wedding tradition. The seven subjects in the study were: 1 patent expert', 1 patone's helper, executing subject: 1 perias, 2 male parents, 2 female parents. The object of the research is the Wedding Tradition of Dayak Kanayatn People in Toho Subdistrict, Mempawah Regency. Qualitative descriptive type research. Data from research subjects' interviews and activities carried out by the Dayak Kanayatn community of Toho Subdistrict, Mempawah Regency. They then reviewed the mathematical aspects based on six basic mathematical activities-one mathematical aspect of the dominant, namely numerate. The saying is seen when Patone' performs nyangahatn, which aims to plead with Jubata to intervene in the Marriage. Pantone' started the activity of saying: asa', dwa, talu, ampat, lima, anam, seven. The number seven is the highest number, meaning fulness.
\end{abstract}

Keywords: Ethnomatematic Studies, Wedding Traditions, Dayak Kanayatn Society

\section{Pendahuluan}

Sukar untuk disangkal bahwa pendidikan terkait dengan proses budaya. Proses ini berlaku untuk semua materi pelajaran termasuk pelajaran matematika. Etnomatematika pada dasarnya merupakan nilai-nilai matematika yang diimplementasikan oleh para leluhur diberbagai belahan dunia dalam melaksanakan aktivitasnya sehari-hari. Sebagaimana diungkapkan oleh para ahli di National Council of Teachers of Mathematics (NCTM) bahwa dalam belajar, membangun hubungan antara budaya sosial, kehidupan pribadi, serta matematika sangatlah penting (NCTM, 2000).

Hubungan yang dapat membangun matematika dan budaya satu diantaranya adalah konsep-konsep etnomatematika yang ditemukan dalam tiap-tiap daerah dan dikelompok budaya tertentu, dan dapat dikombinasikan dalam pembelajaran tingkat sekolah dasar maupun tingkat sekolah menengah pertama. Matematika pada kelompok budaya disebut juga dengan istilah etnomatematika (D'Ambrosio, 1989). 6 aktivitas yang terdapat dalam kajian etnomatematika, yaitu: Aktivitas Membilang, Aktivitas Mengukur, Aktivitas Menentukan Lokasi, Aktivitas Membuat Rancang Bangun, Aktivitas Bermain, serta Aktivitas Menjelaskan.

Istilah etno dapat digambarkan melalui semua hal yang berbentuk identitas dalam budaya-budaya suatu kelompok, yaitu kebiasaan dan sifat-sifat fisik, keyakinan, nilainilai, kode, bahasa, makanan dan pakaian. Sedangkan matematika itu sendiri mencakup pandangan yang sangat luas mengenai mengurutkan, mengklarifikasi, modeling, dan menyimpulkan. Etnomatematika sangat berfungsi untuk mengekspresikan suatu hubungan antara budaya dan matematika. Melalui pernyataan tersebut dapat diambil kesimpulan, bahwa Etnomatematika merupakan ilmu yang dapat digunakan untuk menjelaskan bagaimana matematika itu dapat di adaptasikan dengan sebuah kebudayaan (Marsigit, 2016); (Panjaitan et al., 2021). 
Vol 2 No 2 Desember 2021

Jurnal AlphaEuclidEdu

Received: 05/05/2021; Resived: 11/10/2021; Accepted: 28/12/2021

National Academy of Sciences dalam (Orey, 2006), menjelaskan bahwa budaya mempunyai keberagaman. Keberagaman dalam budaya ini merupakan faktor yang dapat memperkuat dan dapat memberi pengaruh terhadap pembentukan karakter-karakter siswa, bagaimana cara mereka berpikir dalam memahami kehidupan dan dunia yang mereka jalani, dan bagaimana cara mereka untuk menginterpretasikan pengalamannya, bahkan pengalaman orang lain. Oleh sebab itu, pendapat yang dikemukakan oleh (Orey, 2006), bahwa budaya dapat memberi pengaruh terhadap cara memperoleh dan menggunakan pengetahuan terhadap matematika, sehingga strategi dalam etnomatematika dapat diterapkan, yang bertujuan untuk menciptakan dan mengintegrasikan antara budaya yang dimiliki oleh siswa dan matematika dalam suatu pembelajaran matematika.

Etnomatematika merupakan suatu kajian yang mempelajari cara orang dalam mengartiku-lasikan, memahami, serta menggunakan konsep-konsep dan praktik-praktik pada budaya tertentu yang melambangkan segala sesuatu yang matematis. Barton (1996:196), berpendapat bahwa etnomatematika adalah suatu bidang kajian dalam penelitian. Etnomatematika bukanlah matematika dari kelompok budaya tertentu, sebab matematika bukan kumpulan-kumpulan dari bagian matematika yang terpisah, masingmasing satukan dari kelompok yang berbeda-beda. Melainkan etnomatematika merupakan bidang kajian penelitian yang mempelajari suatu ide-ide matematika dalam konteks budaya.

Begitu pula dengan pendapat Orey (2006), mengenai etnomatematika, Ia berpendapat bahwa etnomatematika merupakan himpunan bagian antara antropologi budaya, matematika institusional, dan pemanfaatan pemodelan matematika, yaitu untuk memecahkan masalah nyata serta menerjemahkannya kedalam sistem bahasa matematika. Penyelidikan tentang apa itu budaya merupakan salah satu kajian etnomatematika. Budaya yang menggunakan ide-ide dalam suatu kelompok tertentu.

Implikasi etnomatematika pernikahan merupakan sebuah ikatan yang sah untuk membina rumah tangga dan berkeluarga, karena kedua suami istri bertanggung jawab terhadap keduanya dan anak-anaknya. Pada dasarnya, pernikahan Adat yang dilaksanakan oleh Suku Dayak Kanayatn di Kecamatan Toho, Kabupaten Mempawah, mempunyai bentuk pernikahan yang dipengaruhi oleh sistem kekeluargaan yang bersifat Parental. Parental yang dimaksud adalah sistem kekeluargaan yang menarik garis keturunan baik dari pihak keluarga Ibu maupun dari pihak keluarga Bapak (Nana, 2006).

Puntor (55 tahun) mengemukakan bahwa di Kecamatan Toho khususnya di Desa Sepang, tradisi pernikahan merupakan sebuah acara yang wajib di laksanakan jika ada yang ingin menikah. Dalam hal ini, pernikahan tersebut dilakukan secara ber-Adat. Adat Dayak Kanayatn. Adat kebudayaan Dayak Kanayatn yang selalu digunakan saat prosesi pernikahan akan digelar. Ernst Cassirer (dalam Wahyuni, 2013), mengemukakan bahwa ada 5 aspek dalam kebudayaan, yaitu: (i) Kehidupan spiritual, (ii) Bahasa dan kesastraan, (iii) Kesenian, (iv) Sejarah, dan (v) Ilmu pengetahuan.

Pengetahuan akan dapat berkembang jika matematika yang ada merupakan gagasan dari etnomatematika itu sendiri. Oleh sebab itu, jika pengetahuan mengenai gagasan etnomatematika telah berkembang, maka akan banyak yang melakukan penyelidikan, sehingga matematika dapat diajarkan secara bersahaja dengan mengambil budaya setempat. 
Vol 2 No 2 Desember 2021

Jurnal AlphaEuclidEdu

Received: 05/05/2021; Resived: 11/10/2021; Accepted: 28/12/2021

Budaya yang dimaksud di sini adalah Adat-Istiadat dalam tradisi pernikahan masyarakat Dayak Kanayatn di Kecamatan Toho. Menyangkut masalah sesajian (palantar) yang di hidangkan, pakaian pengantin yang digunakan beserta alat-alat, serta persiapan dalam melaksanakan upacara pernikahan. Penelitian terkait yang dilakukan oleh Sana (2018), ber judul "Perkawinan Adat Dayak Ma'anyan Sebagai Ujud Pendidikan Masyarakat Kalimantan Tengah". Penelitiannya menemukan: Pernikahan merupakan se-suatu yang kodratnya baik dari aspek kebutuhan biologis maupun sosial. Dilihat dari kebutuhan biologis, pernikahan mengarah kepada upaya untuk meneruskan keturunan; sedangkan dari struktur sosial mengarah kepada kelembagaan tradisi atau Adat yang ada di masyarakat.

Penelitian lain dilakukan oleh Noriana (2019), berjudul "Perkawinan Adat Masyarakat Muslim Suku Dayak Ngaju: Sejarah dan Akulturai Islam Terhadap Budaya Lokal di Desa Petak Bahandang". Dalam penelitiannya menemukan: Di Desa Bahandang dalam melaksanakan prosesi pernikahan telah terjadi perubahan, khususnya simbol non-verbal sebagai akibat dari perkembangan jaman dan interaksi antar masyarakat serta masyarakat dalam pernikahan Adat sebagai prosesi yang sakral dari leluhur terdahulu dan masih dilaksanakan hingga sekarang. Dalam penelitiannya Noriana juga mengemukakan, bahwa Suku Dayak Ngaju khususnya umat Muslim berpandangan bahwa Agama dan ke-budayaan merupakan dua hal saling berinteraksi dan saling memberi pengaruh, karena pada keduanya terdapat suatu nilai dan simbol.

Penelitian yang telah dikemukakan di atas dan penelitian yang akan diteliti saat ini memiliki kesamaan konsep, yaitu eksplorasi bentuk-bentuk etnomatematika yang terdapat dalam tradisi pernikahan. Matematika sebagai budaya telah terintegrasi pada segala aspek yang berkaitan dengan pola hidup masyarakat dimanapun mereka tinggal. Maka dapat dikatakan matematika seseorang dapat dipengaruhi oleh lingkungan budaya setempat, sebab apa yang mereka kerjakan berdasar dari apa yang mereka lihat dan mereka rasakan. Budaya sangat berpengaruh bagi prilaku atau sikap individu seseorang dan mempunyai gagasan yang sangat penting pada perkembangan pemahaman individualismenya, termasuk dalam pembelajaran matematika itu sendiri. Pada dasarnya pembelajaran matematika telah menyatu (berkaitan) dengan kehidupan kita sehari-hari.

Budaya dan pendidikan adalah se-suatu yang saling berkaitan. Pendidikan maupun budaya dipandang sebagaimana cara masyarakat mewarisi (mewariskan) tradisi, menemukan gagasan baru dan berevolusi dari generasi ke generasi. Penggunaan budaya dalam pendidikan matematika dapat terjadi karena: (i) Belajar melalui budaya, merupakan penggunaan budaya sebagai sarana dalam belajar, dan (ii) Belajar dengan budaya, merupakan penggunaan budaya sebagai sumber belajar.

Secara umum, prosesi pernikahan Adat Dayak Kanayatn dimulai dengan pinangan dan diakhiri dengan membongkar tingkalakng (seserahan). Terdapat juga beragam ritual yang harus dilaksanakan. Dalam pernikahan Dayak Kanayatn di Desa Sepang tersebut, sangat melarang sebuah pernikahan dilakukan jika kedua mempelai yang masih terikat dengan keluarga. Namun, ada beberapa yang terkadang rela melanggar aturan dengan membayar hukum Adat (denda) sebagai tebusan atas aturan yang mereka langgar. Unsur-unsur matematika yang terkandung dalam ritual pernikahan Adat Dayak Kanayant ini yaitu: jumlah 1 pahar, dalam pahar ini terdiri dari: 2 mangkuk putih, 1 piring yang berisi 7 cucur/tumpi, beras poe'/pulut yang ada dalam 1 bambu, 7 bontokng, 1 piring putih, 3 ayam, 1 babi, 3 cangkir untuk melengkapi Adat. 
Vol 2 No 2 Desember 2021

Jurnal AlphaEuclidEdu

Received: 05/05/2021; Resived: 11/10/2021; Accepted: 28/12/2021

Materi pada hantaran yang dikemaskan yaitu: 7 nasi yang dibungkus dengan daun simpur, 7 nasi pulut yang dibungkus dengan daun layakng, 8 tumpi' (cucur) dibungkus juga dengan daun layakng, 7 ruas sengkatek nasi pulut yang dimasak dalam ruas bambu muda, 1 garam, 1 gula aren (gula enau), 7 linting (gulung) rokok daun, 7 tembakau hitam, dan 7 buah pinang, daun sirih, gembir, dan kapur sirih secukupnya.

Dalam pelaksanaan pernikahan, rombongan mempelai pria akan berangkat menuju rumah mempelai perempuan, namun sebelum berangkat menuju rumah mempelai perempuan, Patone' akan membacakan doa baras banyu terlebih dahulu, yang berbunyi: 'A koa iant kita' Ene' Daniang, Pana Ne' Nange Patampa', Ne' Pajaji, Ne' Pengedokng, Ne' Taratatn, Ne' Amikng, Ne' Pamijar nang nonokng ngalompa; kami talino manusia tamula idup tamula jaji, Siti Awa, Nabi Adam, iant aku maca mamangan baras banyu baras cuci baras aning naing jakita' pama Jubata. Nianlah kami babatak bajahula batampak batarakng ka' kita'. Karana ari naing kami nurutatna' panganten da' Edot dan Rosa, jaji nian unang ia dah turutna' panganten kami minta baras banyu nian kade' ka' pucuk jaji payukng jaji tono'. Kade' ka' tubuh ka' badan ia jaji gunapm barote' jaji palincir palias. Kade' ia ka' tanah ka' saka ka' maraga jaji sabar kuta benteng pagar talutuk jaji jojo danatn. Kade' ada setan ibalis nang ngaco nang ngarua' kami mintak baras banyu nianlah nang mampu mampi' madapnmnya. Karana kami mangka make baras banyu nian Jubata bukaatn uga' numbuh namula mobok marompokng. Nianlah baras banyu nang turutn di ne' Unte' Tanyukng Bunga sae' di Sabaka Samatn di Turintikng Angge Pauh Janggi Petor Kalimantan Tungal nang ngajaratnnya $k a$ ' kami talino manusia Jubata. Kade' panganten nian bajalatn ampa bajalatn $k a^{\prime}$ bide ka' papatn poa' duri poa' onak. Sampe atakng ia ka' rumah nang bibi nang yaknya binia', atakng baraseh atakng salamat. Ahe agi' ke' ia nang pangantena' sampe uga' ka' Pucaranya sampe uga' ka' kami nang ngayukngi'nya sampe uga' $k a$ ' nang bini nang diatakngia' sama baraseh sama salamat nian bah nang kami minta kami mulih Jubata. Asa' dua talu ampat lima anam tujuh koa bajalatn nang kao dolo' baras banyua. Kade' ada jangkang raba' setan balis kao salabih dolo' ngege ngais nyiang muka' ngaramaknya ame ia jaji pangaco pangaru ka' talino manusia jakita' Pama....Jubata".

Artinya: "Ya Tuhan Ya Allah Engkau yang menciptakan dunia ini serta isinya, juga engkau yang menciptakan kami dari tanah liat dan memberi kami nafas kehidupan pada manusia yang pertama Nabi Adam dan Siti Awa. Dengarlah doa kami dengan beras banyu yang 7 biji ini. Biarlah Engkau memberkati beras kuning ini agar menjadi pelindung kami di tengah-tengah perjalanan nanti. Ya Tuhan, karena kami pada hari ini akan menghantarkan mempelai laki-laki kerumah mempelai perempuan yang sekaligus pada hari ini pula akan melangsungkan pernikahan. Tuhan, lindungilah kami semuanya. Tuhan juga mau melindungi mempelai perempuan beserta kaum berkumpul bersamasama dalam keadaan selamat ya Tuhan. Satu dua tiga empat lima enam tujuh, berjalanlah engkau beras banyu yang tujuh biji, karena engkau sudah diberkati oleh Tuhan Yang Maha Kuasa. Biarlah jika engkau diatas menjadi tudung bagi kami. Kalau engkau berada di badan kami biarlah engkau menjadi perisai untuk menyelamatkan kami dari godaan setan iblis. Satu dua tiga empat lima enam tujuh ya...Tuhan".

Etnomatematika mempunyai kerangka, yaitu: Culltural Antropology, Mathematics, Mathematics Modeling. 
Vol 2 No 2 Desember 2021

Jurnal AlphaEuclidEdu

Received: 05/05/2021; Resived: 11/10/2021; Accepted: 28/12/2021

\section{Metode Penelitian}

Penelitian ini menggunakan metode penelitian kualitatif dengan pendekatan etnografi. Hal tersebut dimaksudkan agar dapat mendeskripsikan hasil eksplorasi konsep matematika yang ada pada aktivitas membilang dalam tradisi pernikahan Daya Kanaytn di Desa Sepang, Kecamatan Toho, Kabupaten Mempawahdan dapat mengaplikasikannya kedalam proses pembelajaran matematika.

Terdapat tujuh subjek yang terlibat dalam penelitian ini, yaitu subjek ahli 1 patone', 1 pembantu patone', sedangkan subjek pelaksana yaitu 1 ahli dalam merias, 2 orang tua pengantin mempelai pria, dan 2 orang tua pengantin mempelai wanita.Objek dari penelitian ini yaitu Tradisi Pernikahan Masyarakat Dayak Kanayatn di Kecamatan Toho, Kabupaten Mempawah.

Merancang proposal penelitian adalah langkah awal dalam prosedur penelitian ini, setelah merancang proposal penelitian kemudian dilanjutkan dengan pendeskripsian hasil wawancara dengan 7 subjek penelitian, selanjutnya ditarik kesimpulan agar rumusan masalah yang telah diumuskan dapat terjawab dengan baik.

Penelitian ini dilakukan ditempat kediaman Bapak Molana, yang beralamat di Desa Sepang, Kecamatan Toho, Kabupaten Mempawah. Penelitian ini dilakukan saat putera pertama dari Bapak Molana menikah dengan cara ber-Adat. Penelitian ini dilaksanakan selama 3 hari pada tanggal 18-20 April 2021.

Bentuk wawancara merupakan data yang di peroleh dalam penelitian ini. Berikut adalah beberapa pertanyaan utama yang peneliti tanyakan kepada subjek ahli (Patone') mengenai tradisi pernikahan yang dilaksanakan:

\begin{tabular}{|c|c|}
\hline Pertanyaan & Jawaban \\
\hline $\begin{array}{l}\text { Tadi saat bapak melakukan nyangahatn } \\
\text { saya mendengan bahwa bapak } \\
\text { mengawalinya dengan asa, dwa, talu, } \\
\text { ampat, lima, anam, tujuh. Maksudnya } \\
\text { apa? }\end{array}$ & $\begin{array}{l}\text { "Kata asa, dwa, talu, ampat, lima, anam, } \\
\text { tujuh ini mempunyai arti bahwasannya } \\
\text { kita ingin memulai berinteraksi dengan } \\
\text { Jubata agar turut campur dalam } \\
\text { pelaksanaan pernikahan ini." }\end{array}$ \\
\hline Mengapa diakhiri dengan angka tujuh? & $\begin{array}{l}\text { "Karena memang tadisi kita seperti ini, } \\
\text { tradisi yang telah dilakukan turun } \\
\text { temurun" }\end{array}$ \\
\hline Mengapa tidak ada angka nol? & $\begin{array}{l}\text { "Karena dalam pelaksanaan nyangahatn } \\
\text { tidak mengenal angka nol." }\end{array}$ \\
\hline $\begin{array}{l}\text { Apa itu Adat dalam tradisi pernikahan } \\
\text { Dayak Kanayatn? }\end{array}$ & $\begin{array}{l}\text { "Adat dalam tradisi pernikahan Dayak } \\
\text { Kanayatn merupakan sebuah ritual (ritual } \\
\text { nyangahatn)." }\end{array}$ \\
\hline
\end{tabular}

Instrument utama pada penelitian ini adalah peneliti sendiri, dan instrument lainnya merupakan instrumen pendukung, berupa: kamera, alat rekam, pertanyaan wawancara.

\section{Hasil Dan Pembahasan}


Vol 2 No 2 Desember 2021

Jurnal AlphaEuclidEdu

Received: 05/05/2021; Resived: 11/10/2021; Accepted: 28/12/2021

Berdasarkan wawancara kepada 7 subjek pada tanggal 18-20 April 2021, peneliti menemukan satu aspek matematis yang dominan, yaitu membilang. Aspek membilang nampak ketika Patone' (pemimpin upacara) melakukan aktifitas nyangahatn. Nyangahatn bertujuan memohon kepada Jubata agar turut campur dalam pelaksanaan Pernikahan. Patone' (pemimpin upacara) mengawali dengan aktifitas membilang: asa', $d w a$, talu, ampat, lima, anam, tujuh. Angka tujuh merupakan angka paling tinggi yang mempunyai makna kegenapan (keterlibatan Jubata dalam pelaksanaan pernikahan).

Penelitian ini bertujuan untuk mengetahui Adat Istiadat Dayak Kanayatn sebagai aspek matematis dalam prosesi pernikahan yang berkaitan dengan kajian etnomatematika, sehingga dapat digunakan dalam belajar mengajar matematika disekolah dan tidak harus terpaku dengan bahan ajar, melainkan dari kebiasaaan seharihari juga dapat dikaitkan dengan pembelajaran, khususnya pembelajaran matematika.

Contoh: kebiasaan dalam mengikuti sebuah tradisi pernikahan yang diadaka. Sebuah tradisi atau kebiasaan yang sering kali diadakan dari tahun ketahunnya. Begitu pula dengan masyarakat Dayak Kanayatn di Desa Sepang Kecamatan Toho, Kabupaten Mempawah, yang selalu mengadakan tradisi pernikahan jika ada sanak saudaranya yang hendak disatukan sehingga tercipta sebuah keluarga. Dalam pelaksanaan tradisi pernikahan di Desa Sepang, Kecamatan Toho ini menemukan sebuah aspek yang lebih dominan, yaitu membilang.

\section{Simpulan}

Berdasarkan hasil penelitian dapat di ambil kesimpulan: Dalam pelaksanaan pernikahan Dayak Kanayatn di Kecamatan Toho, Kabupaten Mempawah terdapat satu aspek yang dominan, yaitu membilang.

Aspek membilang ini nampak ketika Patone' melakukan nyangahatn yang diawali dengan ucapan: asa dwa talu ampat lima anam tujuh. Angka ujuh adalah angka paling tinggi yang mempunyai makna kegenapan.

\section{Referensi}

Barton, B. (1996). Making Sense Of Etnhomathematics: Ethnomathematics Is Making Sense. Educational Studies In Mathematics. [diakses, 11 Februari 2021].

D'Ambrosio, U. On ethnomathematics. 1989. Philosophica Mathematica (2) 4 no.1, 3 14 [diakses, 15 Februari 2021].

Hartoyo, A. 2012. Eksplorasi Etnomatematika pada Budaya Masyarakat Dayak Perbatasan Indonesia-Malaysia Kabupaten Sanggau Kalbar. Jurnal Penelitian Pendidikan, 13 (1) [diakses, 20 November 2020].

National Council of Teacher of Mathematics. (2000). Principles And Standarts For School Mathematics. School Science And Mathematics (Vol 47). [diakses, 25 Februari 2021].

Noriana, 2019 - Perkawinan Adat Masyarakat Muslim Suku Dayak Ngaju: Sejarah dan Akulturasi Islam Terhadap Budaya Lokal di Desa Petak Bahandang. [diakses, 20 November 2020].

Orey, Daniel Clark \& Rosa, Milton. 2006. Etnomathematics: Cultural Assertions And Challenges Towards Pedagogical Action. The Journal Of Mathematics And Culture. [diakses, 11 September 2020].

Panjaitan, S., Hartoyo, A., \& Fitriawan, D. (2021). Eksplorasi Etnomatematika Kain 
Vol 2 No 2 Desember 2021

Jurnal AlphaEuclidEdu

Received: 05/05/2021; Resived: 11/10/2021; Accepted: 28/12/2021

Tenun Songket Suku Melayu Sambas. Jurnal AlphaEuclidEdu, 2(1), 19-31. https://jurnal.untan.ac.id/index.php/AlphaEuclidEdu/article/view/47890

Puntor (usia 55 Tahun) Selaku Ketua Adat di Desa Sepang, Kecamatan Toho, Kabupaten Mempawah. [diakses, 25 September 2020].

Sintani Sana, 2018 - Perkawinan Adat Dayak Ma'anyan Sebagai Ujud Pendidikan Masyarakat. [diakses, 20 November 2020].

Wahyuni, A., dkk. 2013. Peran Etnomatematika dalam Membangun Karakter Bangsa. Prosiding ISBN : 978-979-16353-9-4. Makalah dipresentasikan dalam Seminar nasional Matematika dan Pendidikan Matematika dengan tema "Penguatan Peran Matematika dan Pendidikan Matematika untuk Indonesia yang Lebih Baik" [diakses, 15 Oktober 2020]. 